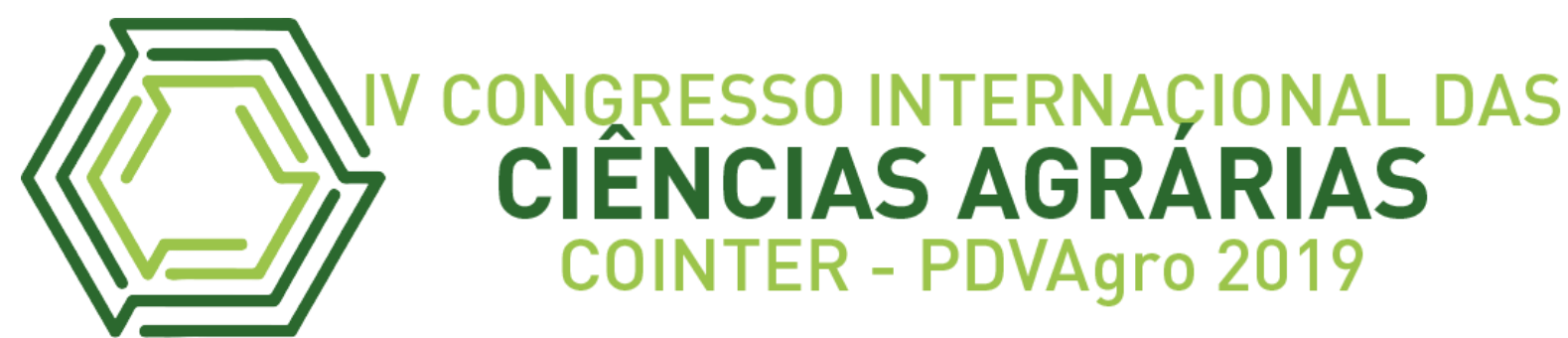

\title{
BIOMETRIA E TROCAS GASOSAS EM MUDAS DE AÇAIZEIRO INOCULADAS COM BIOFERTILIZANTES
}

\author{
BIOMETRÍA E INTERCAMBIOS DE GAS EM PLÁNTULAS DE ACAI \\ INOCULADAS COM BIOFERTILIZANTES
}

\section{BIOMETRY AND GAS EXCHANGES IN ACAI SEEDLINGS INOCULATED WITH BIOFERTILIZERS}

\author{
Apresentação: Comunicação Oral
}

\begin{abstract}
Alice de Paula de Sousa Cavalcante ${ }^{1}$; Gleiciane Rodrigues dos Santos ${ }^{2}$; Rafael Rodrigo da Silva Costa $^{3}$;Vitoria Cunha Martins ${ }^{4}$; Gisele Barata da Silva ${ }^{5}$.
\end{abstract}

DOI: https://doi.org/10.31692/2526-7701.IVCOINTERPDVAgro.2019.0053

\section{Resumo}

As sementes de açaizeiro apresentam germinação heterogênea e baixa taxa de crescimento entre o semeio e a obtenção de mudas. O objetivo do estudo foi avaliar a biometria e trocas gasosas em mudas de açaizeiro inoculadas com os biofertilizantes compostos por rizobactérias e o Mix de Trichoderma asperrellum. Os tratamentos consistiram das inoculações individuais de seis isolados de rizobactérias, Mix de Trichoderma e um controle (inoculados com água) nas raízes das mudas de açaizeiro. Os dados de biometria e biomassa foram submetidos a análise de agrupamento, e as médias dos grupos foram comparadas pelo teste $\mathrm{SNK}(P<0,05)$. Três grupos foram formados, sendo o grupo 1 composto pelo controle, o grupo 2 composto pelas Rizobactérias (R-46, R-55, R-58, R-61 e R-92) e o grupo 3 composto pelo Mix de Trichoderma (T06, T09, T12 e T52). Os isolados dos grupos 2 e 3 promoveram aumento no crescimento, conteúdo de clorofilas e melhoria nos parâmetros de trocas gasosas. As mudas de açaizeiro inoculadas com Mix de Trichoderma asperrellum promoveram aumento no crescimento em $47 \%$ e no desempenho fotossintético, nos parâmetros de trocas gasosas, em $34 \%$ para $A$, em $52 \%$ para $g_{\mathrm{s}} \mathrm{e}$, em $56 \%$ para $E$, em comparação ao grupo 1 . O isolado pertencente ao grupo 3 pode contribuir para o manejo sustentável de mudas de açaizeiro em

\footnotetext{
${ }^{1}$ Agronomia, Universidade Federal Rural da Amazônia, alicecavalcantee@yahoo.com

${ }^{2}$ Agronomia, Universidade Federal Rural da Amazônia, anerodrigues_31@hotmail.com

${ }^{3}$ Agronomia, Universidade Federal Rural da Amazônia, rafaelrodrigo1992@hotmail.com

${ }^{4}$ Agronomia, Universidade Federal Rural da Amazônia, martinsvitoria507@gmail.com

${ }^{5}$ Doutora em Agronomia, Universidade Federal Rural da Amazônia, giselebaratasilva@gmail.com
} 
viveiros, pois atua como promotor de crescimento e aumenta a eficiência fotossintética das mudas de açaizeiro.

Palavras-Chave: Biopromotores, Euterpe oleracea, Germinação, Fotossíntese

\begin{abstract}
Resumen
Las semillas del árbol de acai (Euterpe oleraceae Mart.) Tienen uma germinación heterogénea y yna baja tasa de crecimiento entre la siembra y las plântulas. El objetivo fue evaluar la biometría y el intercambio de gases em plântulas de acai inoculadas com biofertilizantes compuestos por Rhizobacteria y Trichoderma. Los tratamientos consistieron em inoculaciones individuales de seis aislados de Rhizobacteria, una mezcla de cuatro aislados inoculaciones individuales de seis aislados de Trichoderma y yn control (rociado com agua) en las raíces de las plántulas de acai. Los datos biométricos y de biomassa se sometieron a análisis de conglomerados, y las medias grupales se compararon mediante la prueba SNK $(\mathrm{P}<0.05)$. Se formaron tres grupos: el grupo 1 compuesto por el control, el grupo 2 compuesto por Rhizobacteria (R-46, R-55, R-58, R-61 y R-92) y el grupo 3 por T.Mix (T06, T-09, T-12 y T-52). Los aislamientos de los grupos 2 y 3 promovieron el aumento en el crecimiento, el contenido de clorofila y la mejora en los parámetros de intercambio de gases. Las plantas inoculadas con Trichoderma promovieron un aumento del $47 \%$ en el crecimiento y el rendimiento fotossintetico en los parámetros de intercambio de gases, 34\% para A, 52\% para gs, $56 \%$ para E y $32 \% \mathrm{Ci}$ en comparación con el grupo 1. El biofertilizante Trichoderma puede contribuir al manejo sostenible de las plántulas de acai en viveros, ya que actúa como un promotor del crecimiento y aumenta la eficiencia fotossintetica de las plántulas de acai.
\end{abstract}

Palabras Clave: Biopromotores, Euterpe oleraceae, germinación, fotossínteses.

\begin{abstract}
The acai seeds have heterogeneous germination and low growth rate between sowing and seedlings. The aim of this study was to evaluate the biometrics and gas exchange in açaí tree seedlings inoculated with rhizobacteria biofertilizers and Trichoderma asperrellum mix. The treatments consisted of the individual inoculations of six rhizobacteria isolates, a Trichoderma Mix and a control (inoculated with water) in the roots of the acai. Biometrics and biomass data were subjected to cluster analysis, and group means were compared by SNK test (P $<0.05)$. Three groups were formed, being group 1 composed of the control, group 2 composed of rhizobacteria (R-46, R-55, R-58, R-61 and R-92) and group 3 composed of Trichoderma Mix (T06, T09, T12 and T52). The isolates of groups 2 and 3 promoted increase in growth, chlorophyll content and improvement in gas exchange parameters. The seedlings inoculated with Trichoderma asperrellum Mix promoted growth of $47 \%$ and photosynthetic performance in gas exchange parameters, $34 \%$ for A, $52 \%$ for gs, $56 \%$ for E compared to group 1 . The isolate belonging to group 3 can contribute to the sustainable management of acai seedlings in nurseries, $\mathrm{o}$ it acts as a growth promoter and increases the photosynthetic efficiency of acai seedlings.
\end{abstract}

Keywords: Biopromotors, Euterpe oleracea, Germination, Photosynthesis 


\section{Introdução}

O açaizeiro (Euterpe oleracea Mart.) é um importante recurso genético da Amazônia, explorado principalmente pelos seus frutos, palmito e produção de biojóias, que, nos últimos anos, vem despertando interesse para o cultivo, visando à produção de frutos (OLIVEIRA et al., 2002), pois recentemente tornou-se popular como alimento funcional, devido ao seu potencial antioxidante, o que contribui para melhoria da saúde humana (RUFINO et al., 2011). O alto consumo dos frutos estimulou a expansão dos plantios comerciais em grandes áreas de terra firme (RUFINO et al. 2011). Porém, a pouca disponibilidade de sementes e material genético diferenciado limitam a produção de mudas de açaizeiro em viveiros (MARTINS-CORDER; SALDANHA, 2006; MARTINS; NAKAGAWA; BOVI, 2009).

O processo de germinação das sementes de açaí é relativamente lento e desuniforme (NASCIMENTO, 2007; SILVA et al., 2007). A emergência das plântulas se inicia por volta de 20 dias após a semeadura e estabiliza-se por volta dos 45 dias (QUEIRÓZ; MOCHIUTTI, 2001) A comissão estadual de sementes e mudas do Pará (1997), estabeleceu normas e padrões de mudas de açaizeiro que devem ter de 4 a 6 meses e apresentar de 40 a $60 \mathrm{~cm}$ de altura com crescimento uniforme, possuir no mínimo 5 folhas fisiologicamente ativas e aspecto vigoroso.

As dificuldades enfrentadas na germinação heterogênea e baixa taxa de crescimento entre o semeio e a obtenção de mudas que dificultam a produção em larga escala para comercialização. No entanto, algumas estratégias podem ser implantadas para amenizar esses problemas como o uso de microrganismo do solo como as rizobactérias e o fungo Trichoderma.

Vários estudos relatam o uso desses microrganismos para promover o crescimento de mudas de palmeiras, como palma de óleo (OM et al. 2009) e coqueiro (GEORGE et al. 2013). Os benefícios incluem maior reciclagem, solubilização e absorção de nutrientes minerais, síntese de vitaminas, aminoácidos, sideróforos e hormônios promotores do crescimento de plantas, como giberelina, auxina e citocinina (VAN LOON 2007; GLICK 2012; CHAUDHARY; SINDHU 2016). Os efeitos do Trichoderma na promoção do crescimento 
têm sido evidenciados pelo aumento da biomassa, pela absorção e translocação de nutrientes como P, Zn, Mn e Fe, pelo aumento da resistência a estresse biótico e abiótico, pela germinação de sementes, promoção do crescimento e aumento da produtividade (HOYOSCARVAJAL et al, 2009; SILVA, et al., 2012).

Desta forma, este trabalho teve como objetivo selecionar um biofertilizante composto por rizobactéria ou Trichoderma que acelere o crescimento em mudas de açaizeiro e aumente a taxa fotossintética das mudas de açaizeiro.

\section{Fundamentação Teórica}

O açaizeiro é uma cultura de grande importância econômica para alguns estados da região Norte e Nordeste do Brasil. O estado do Pará é o maior produtor dessa palmeira, que tem como produto primário o suco de açaí, consumido por boa parte da população nortista, fazendo parte da dieta alimentar dos paraenses. O aumento do consumo do fruto está relacionado às suas propriedades nutricionais, com destaque para o teor de lipídeos (ácidos graxos insaturados), proteínas, fibras e minerais e teores de compostos antioxidantes, entre eles as antocianinas (ALEXANDRE et al., 2004) e os carotenoides (RIBEIRO et al., 2010).

$\mathrm{Na}$ década de 1990, para suprir o aumento da demanda pelo consumo do açaí, a produção de frutos passou a ser obtida de açaizais nativos manejados em solos de várzea e de terra firme com cultivares melhoradas geneticamente pela Embrapa como a cultivar BRS Pará (OLIVEIRA; NETO, 2004). A maior demanda pelo açaí, gerou necessidades de mudanças no sistema produtivo dos açaizeiros. Estes, que antes eram apenas manejados em áreas de várzea, começaram a ser cultivados em áreas de terra firme, sendo necessárias mudas vigorosas, sistema de irrigação e manejo da adubação. Para atender a demanda do mercado, alguns fatores limitantes devem ser superados, como o tempo para formação de mudas com o padrão morfológico exigido pelo Ministério da Agricultura, Pecuária e Abastecimento - MAPA.

Segundo o MAPA, as mudas de açaizeiro, para serem comercializadas, devem apresentar as seguintes características: altura entre 40 a $60 \mathrm{~cm}$, cinco folhas expandidas, sendo estas fotossinteticamente ativas, diâmetro da base do coleto maior que o do ápice e sistema radicular bem desenvolvido. Contudo, essas características são obtidas oito meses após o semeio, tempo suficiente para que as mudas, em condições de viveiro, estejam sujeitas ao surgimento de doenças e ao excesso de aplicação de adubos minerais. No entanto, o sucesso da implantação e o desenvolvimento de açaizais em áreas de terra firme depende de mudas de 
qualidade, resistentes e tolerantes a condições limitantes. A aplicação de insumos químicos é uma das principais práticas de manejo na agricultura moderna, adubação química fornece nutrientes essenciais ao crescimento e desenvolvimento das plantas, porém o uso exagerado destes produtos gera uma série de impactos negativos ao solo, devido a acumulação de metais pesados (ADSEMOYE et al., 2009).

Nesse contexto, os produtos formulados a partir de microrganismos promotores de crescimento de plantas, atuam de diferentes formas para garantir o desenvolvimento vegetal, pois podem ser: biofertilizantes, bioestimulantes e biocontroladores de pragas e doença, com isso a aplicação de microrganismos é vista como uma alternativa de reduzir o uso de adubação química fornecendo assim uma produção sustentável (SILVESTRE et al., 2016; CASTRO et al., 2017).

Os microrganismos promotores do crescimento de plantas, como as rizobactérias e fungos do gênero Trichoderma são organismos de vida livre, habitantes naturais do solo que fazem associação simbiótica com as plantas, colonizando suas raízes (HALDAR; SENGUPTA, 2015). Por meio de alguns mecanismos, estes microrganismos conseguem otimizar a promoção de crescimento das plantas, aumentando sua biomassa de parte aérea e raízes, devido alterações fisiológicas e metabólicas estimuladas por eles, como a produção de fitohormônios, bem como devido ao acúmulo nutricional nas plantas, por meio da solubilização de nutrientes no solo. Além disso, os microrganismos promotores do crescimento de plantas são uma tecnologia mais limpa e menos nociva ao meio ambiente, garantindo uma agricultura mais sustentável, econômica, social e ambientalmente.

A associação simbiótica entre plantas e microrganismos ocorre inicialmente no sistema radicular das plantas, no qual os microrganismos atraídos pelos metabólitos expelidos das raízes iniciam o processo de colonização na mesma, fornecendo diversos benefícios e modificações fisiológicas e anatômicas na planta. Contudo apesar da crescente quantidade de dados na literatura descrevendo os benefícios desses biofertilizantes, poucos dados se referem a promoção de crescimento e trocas gasosas em mudas de açaizeiro inoculadas com rizobactérias e Trichoderma. $\mathrm{O}$ uso desses microrganismos, considerados como bioestimulantes, na produção de mudas, reduz o tempo de viveiro, reduzindo, consequentemente, o custo de produção, devido à diminuição da demanda por insumos químicos. As mudas atingem, mais rapidamente, o padrão morfológico ideal, podendo com 5 meses, serem comercializadas e transplantadas no campo (CASTRO et al., 2017). 


\section{Metodologia}

\section{Preparo de mudas}

Sementes de açaizeiro (cultivar BRS-Pará) foram semeadas em bandejas de plástico contendo 2,5 L de substrato composto de fibra de coco triturada (Golden mix). Aos 32 dias após a germinação, as plântulas que apresentaram duas folhas expandidas e altura próxima de $13 \mathrm{~cm}$ foram transplantadas para sacos de plástico $(15 \times 25 \mathrm{~cm}$, comprimento $\mathrm{x}$ altura) contendo substrato composto de $60 \%$ de Latossolo e $40 \%$ de cama de aviário curtida. O cultivo foi realizado no viveiro da Universidade Federal Rural da Amazônia em Belém, PA, que apresenta características climáticas do tipo AMI de acordo com a classificação de Koppen-Geiger. Durante o período experimental (fevereiro a agosto de 2017) as condições ambientais foram de $32 \pm 2^{\circ} \mathrm{C}$ de temperatura do ar,75 $\pm 5 \%$ de umidade relativa, $2 \pm 0,2 \mathrm{kPa}$

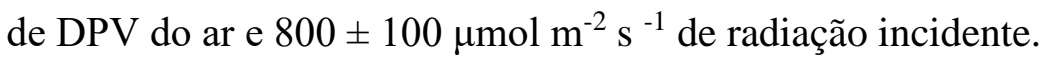

\section{Isolados de Rizobactérias e Trichoderma asperrellum}

Os isolados de Rizobactérias (R 46, R 55, R58, R61 e R 61) e T. Mix (T06, T09, T12 e T52) utilizados no ensaio são provenientes da coleção de microrganismos do Laboratório de Proteção de Plantas (LPP) da Universidade Federal Rural da Amazônia-UFRA, campus Belém.

\section{Inoculação das rizobactérias e Trichoderma asperrellum}

As rizobactérias (R-46, R-55, R-58, R-61 e R-92) foram cultivadas em meio sólido 523 (Kado and Heskett 1970) durante 48 h, a $28{ }^{\circ} \mathrm{C}$. As suspenções bacterianas foram preparadas com água destilada e esterilizada, e a concentração foi ajustada em espectrofotômetro para A540 = 0,5 (10 $\left.{ }^{8} \mathrm{UFC}\right)$. Os isolados de Trichoderma asperrellum (T06, T09, T12 e T52) foram primeiramente cultivados em meio sólido BDA (batata, dextrose e ágar) durante $96 \mathrm{~h}$, a $28^{\circ} \mathrm{C}$. A partir dessas placas, foram preparadas suspensões de conídios, 
ajustadas em câmara de Neubauer para $1 \times 10^{8}$ conídios $\mathrm{mL}^{-1}$. As suspensões foram utilizadas como inóculo inicial sob o arroz parboilizado esterilizado em frascos Erlenmeyers de 1000 $\mathrm{mL}$ na proporção de $250 \mathrm{~g}$ de arroz para $4 \mathrm{~mL}$ da suspensão fúngicas do Mix de Trichoderma (T06, T09, T12 e T52).

As plântulas tiveram suas raízes seccionadas para padronização do comprimento radicular em $7 \mathrm{~cm}$ e, antes do transplantio para os sacos plásticos com o substrato, foram imersas em $500 \mathrm{~mL}$ de cada suspensão bacteriana e fúngica durante 20 min. As plântulas controle foram imersas em água destilada e esterilizada. Em seguida, foi realizada uma irrigação por semana durante um mês com $50 \mathrm{~mL} /$ plântula de cada suspenção bacteriana e fúngica para plantas tratadas, e com $50 \mathrm{~mL} /$ plântula de água destilada e esterilizada para as plantas controle. Após esse período, foi mantida uma irrigação a cada mês até o terceiro mês de idade das mudas de açaizeiro.

\section{Avaliação do crescimento e biomassa}

A promoção do crescimento foi avaliada aos cinco meses após a germinação das sementes. A altura das plantas e o diâmetro do coleto foi mensurado com paquímetro digital (precisão de 0,02 mm). O índice de robustez foi calculado pela razão entre a altura da planta e diâmetro do coleto. O número de folhas foi avaliado através da contagem direta das folhas.

\section{Trocas gasosas}

As plantas de açaizeiro foram avaliadas quanto a trocas gasosas, com um sistema portátil de fotossíntese (LI-6400XT; LI-COR, Lincoln, NE). A taxa líquida de assimilação de $\mathrm{CO}_{2}(A)$, condutância estomática $(g s)$, transpiração $(E)$ e concentração intercelular de $\mathrm{CO}_{2}$ $\left(C_{\mathrm{i}}\right)$. Foram avaliados na segunda folha fisiologicamente madura e completamente expandida, do ápice para a base, aos cinco meses após a inoculação das Rizobactérias (R-46, R-55, R-58, R-61 e R-92) e do Mix de Trichoderma (T06, T09, T12 e T52) a uma concentração de $\mathrm{CO}_{2}$ $400 \mu \mathrm{mol} \mathrm{mol}{ }^{-1}$ de ar e radiação fotossinteticamente ativa (PAR) artificial de $900 \mu \mathrm{mol}$ de fótons $\mathrm{m}^{-2} \mathrm{~s}^{-1}$.

\section{Análise estatística}


O experimento foi realizado em delineamento inteiramente casualizado com sete tratamentos seis isolados de rizobactérias, Mix de Trichoderma e o controle (sem rizobactéria ou Trichoderma) e quatro repetições. Os dados de crescimento foram submetidos à análise de agrupamento usando os valores médios de cada indivíduo e o grau de similaridade foi obtido pela distância Euclidiana padrão. Os grupos foram submetidas à análise de variância (ANOVA) e as médias foram comparadas pelo teste Student-Newman-Keuls (SNK), $P<$ 0,05 , usando o software R versão 3.1 .

\section{Resultados e Discussão}

Todos os isolados testados promoveram o crescimento das mudas de açaizeiro (Tabela 1). A análise de agrupamento revelou a formação de três grupos, onde o tratamento controle composto pelo grupo 1 foi inferior para todas as variáveis de promoção de crescimento em relação aos grupos 2 e 3, composto pelos isolados (R-46; R-55; R-58; R-61 e R-92); e o Mix de Trichoderma (T06; T09; T12 e T52), respectivamente. Para as variáveis de crescimento, o aumento variou entre 23 e $47 \%$ para a altura de planta, em 19 e 32\% para o diâmetro do coleto, o número de folha em $38 \%$ e, em 3 e 17\% para o índice de robustez para os isolados dos grupos 2 e 3, respectivamente em comparação com o grupo 1 .

No presente estudo, o grupo 3 induziu maior diâmetro do coleto e aumento do índice de robustez em mudas de açaizeiro inoculadas com Mix de Trichoderma, parâmetro que está relacionado ao maior vigor das mudas. Resultados semelhantes foram encontrados para outros biopromotores de crescimento, como rizobactérias inoculadas em mudas de coco (GEORGE et al. 2013).

Tabela 1: Avaliação biométrica em mudas de açaizeiro (6 meses), inoculadas com biopromotores de crescimento em relação ao controle.

\begin{tabular}{cccccc}
\hline${ }^{\mathrm{a} G r u p o s}$ & ${ }^{\mathrm{b}}$ Isolados & $\begin{array}{c}{ }^{\mathrm{c}} \mathrm{ALT} \\
(\mathrm{cm})\end{array}$ & ${ }^{\mathrm{c}} \mathrm{NF}$ & ${ }^{\mathrm{c}} \mathrm{DC}(\mathrm{mm})$ & ${ }^{\mathrm{c}} \mathrm{IR}$ \\
\hline 1 & Controle & $44,37 \mathrm{c}$ & $3,25 \mathrm{~b}$ & $8,97 \mathrm{~b}$ & $5,00 \mathrm{~b} \mathrm{a}$ \\
& $\begin{array}{c}\text { R 46; R 55; R 58; } \\
\text { R 61; R 92 }\end{array}$ & $54,43 \mathrm{~b}$ & $4,31 \mathrm{a}$ & $10,65 \mathrm{a}$ & $5,19 \mathrm{ab}$ \\
3 & Mix de Trichoderma & $65,25 \mathrm{a}$ & $4,5 \mathrm{a}$ & $11,9 \mathrm{a}$ & $5,83 \mathrm{a}$ \\
\hline $\mathrm{CV}(\%)$ & & 11,2 & 8,96 & 10,18 & 9,54 \\
\hline
\end{tabular}


${ }^{a}$ Grupos de similaridade de acordo com a matriz Euclidiana; ' ${ }^{2}$ ssolados de rizobactérias ( R 46, R 55, R 58, R 61 e R 92) e o Mix de Trichoderma asperrellum (T06, T09, T12 e T52) e cAvaliações biométricas: Altura em cm (ALT), Número de folhas (NF), Diâmetro do coleto em mm, (DC) e Índice de robustez (IR).*Médias com letras iguais não diferem significativamente de acordo com o teste Student-Newman-Keuls $(\mathrm{P}<0,05)$.

O presente estudo demonstrou a ação positiva dos grupos 2 e 3 como promotores de crescimento. Vários estudos relatam os benefícios da inoculação das rizobactérias e do Trichoderma na promoção do crescimento em monocotiledôneas como palma de óleo (OM et al. 2009), coqueiro (GEORGE et al. 2013), feijão (CARVALHO et al. 2011), e arroz (FILIPPI et al. 2011; RAIS et al. 2016, BUENO et al. 2017), que resultou em aumento no crescimento do sistema radicular e eficiência na absorção de água e nutrientes.

O crescimento da parte aérea, assim como do número de folhas observados no grupo 2 e 3 (Figura 1) pode ser atribuído a capacidade das rizobactérias e do Mix de Trichoderma de induzir a síntese de giberelinas e citocininas que regulam a expansão foliar e síntese de clorofilas (DODD et al. 2010; KANG et al. 2014). Além disso, o maior crescimento da parte aérea inclui maior número de folhas e expansão da aérea foliar, o qual contribui para maior captação luz e assimilação de $\mathrm{CO}_{2}$ (ZHANG et al. 2017). Nascente et al, (2016) relataram que a aplicação de microrganismos como Serratia sp. (BRM32114), Bacillus sp. (BRM32110 and BRM32109) e o Mix de Trichoderma asperellum promoveram um aumento na taxa fotossintética e na biomasssa seca da folha em planta de arroz.

Figura 1. Aspecto visual da parte aérea das mudas de açaizeiro (cinco meses de idade) inoculadas com biofertilizantes pertencentes ao grupo 1 (Controle), grupo 2 (Rizobactérias) e grupo 3 (Mix de Trichoderma).

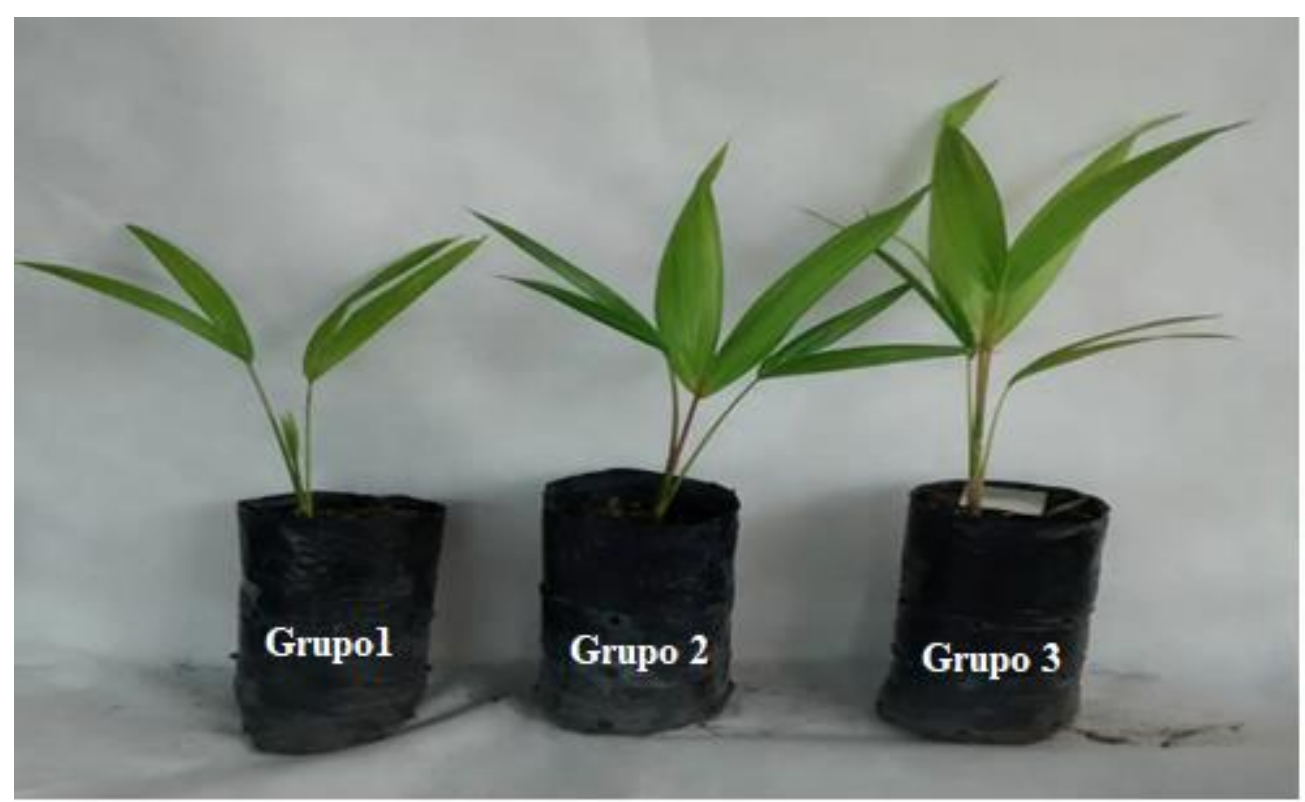

Fonte do autor 
Mukherjee et al. (2012), relataram que a presença de Trichoderma na rizosfera evoca uma resposta proteômica e metabólica na planta e aumenta a eficiência fotossintética em plantas tratadas. A inoculação de Trichoderma harzianum em plantas de avelã aumentou a taxa fotossintética em $24,4 \%$, condutância estomática em $31,4 \%$ e a eficiência do uso da água em 22,4\% (ROSTAMIKIA et al, 2017).

No presente estudo, todos os isolados dos grupos 2 e 3 induziram aumento nas trocas gasosas em comparação ao grupo 1 (controle). Os aumentos variaram entre 21 e $34 \%$ para A, em 34 e $52 \%$ para $g$ s e, em 36 e $56 \%$ para $E$ nos grupos 2 e 3, respectivamente (Tabela 2). Dentre os microrganismos utilizados na avaliação de trocas gasosas o Mix de Trichoderma, destacou-se com aumento na taxa de assimilação líquida de carbono $(A)$, condutância estomática ao vapor de água $(g s)$ e taxa de transpiração $(E)$.

As mudas de açaizeiro inoculadas com os biofertilizantes não apresentaram diferença estatísticas para variável de concentração intercelular de $\mathrm{CO}_{2}(C \mathrm{i})$, provavelmente os biofertilizantes pertencentes do grupo 2 e 3, podem modular a atividade de carboxilação da Rubisco através da maior fixação de $\mathrm{CO}_{2}$ para a produção de carboidratos. Resultados semelhantes foram encontrados para outros biopromotores de crescimento, como Trichoderma spp. inoculados em plantas de arroz (DONI et al. 2014). Esses benefícios podem resultar em maior produção de fotoassimilados, como sacarose e rafinose, os quais podem ser alocados para órgãos heterotróficos das plantas para sustentar o crescimento ou serem convertidos em produtos de reversas (SHI et al. 2010) ou ser utilizados pelas rizobactérias pelos exsudados radiculares (BAIS et al. 2006).

Tabela 2. Avaliação de trocas gasosas em mudas de açaizeiro tratadas com duas regas de suspensão com microrganismos promotores de crescimento.

\begin{tabular}{cccccc}
\hline \multirow{2}{*}{${ }^{\mathrm{a}}$ Grupos } & bIsolados & \multicolumn{4}{c}{${ }^{\mathrm{c} T r o c a s}$ gasosas } \\
\cline { 3 - 6 } & Controle & $11,67 \mathrm{~b}$ & $357,14 \mathrm{a}$ & $0,0563 \mathrm{~b}$ & $1,3512 \mathrm{~b}$ \\
\hline 1 & R-46; R-55; R-58; & $14,17 \mathrm{a}$ & $353,62 \mathrm{a}$ & $0.0756 \mathrm{ab}$ & $1,8483 \mathrm{ab}$ \\
2 & R-61; R-92 & Ci & Gs & $\mathrm{E}$ \\
3 & Mix de Trichoderma & $15,61 \mathrm{a}$ & $360,05 \mathrm{a}$ & $0,0849 \mathrm{a}$ & $2,1107 \mathrm{a}$ \\
\hline $\mathrm{CV}(\%)$ & & 12,37 & 1,41 & 22,63 & 20,98 \\
\hline
\end{tabular}

${ }^{\mathrm{a}}$ Grupos de similaridade de acordo com a matriz Euclidiana; ${ }^{\mathrm{b}}$ Isolados de rizobactérias ( R 46, R 55, R 58, R 61 e R 92) e o MIX de Trichoderma asperrellum (T06, T09, T12 e T52) e cAvaliações de trocas gasosa: (A) Taxa 
de assimilação líquida de $\mathrm{CO}_{2},(\mathrm{Ci})$ Concentração intercelular de $\mathrm{CO}_{2}$, $(\mathrm{gs})$ Condutância estomática ao vapor de água e $(E)$ Transpiração.*Médias com letras iguais não diferem significativamente de acordo com o teste de Student-Newman-Keuls $(\mathrm{P}<0,05)$.

As rizobactérias e o T. Mix induziram aumento a assimilação líquida de CO2 (A) em relação as plantas controle, porém, essas diferenças foram mais contundentes para o grupo 3 (T. Mix). O maior valor de $A$ pode ser atribuído ao maior grau de abertura dos estômatos (gs), o qual permite a maior entrada de $\mathrm{CO}_{2}$ nas folhas e favorece o aumento da fotossíntese líquida. Em plantas de arroz inoculadas com rizobactérias foi observado aumento na taxa de fotossintética líquida, o qual foi atribuído a influência positiva na abertura e fechamento dos estômatos, que afetou diretamente as trocas gasosas e contribuiu para o crescimento da planta (NASCENTE et al. 2016).

As mudas do grupo 2 e 3 apresentaram maior taxa de transpiração pode ser atribuída a maior abertura estomática induzida por todas as rizobactérias e o Mix de Trichoderma asperrellum. Entretanto, o grupo 3 (Mix de Trichoderma) induziu maior taxa de transpiração, provavelmente está correlacionado a maior abertura estomática e maior área foliar total e menor razão raiz / parte aérea. Quando a água é abundante e a radiação solar incidente nas folhas favorece a alta atividade fotossintética, há elevada demanda por $\mathrm{CO}_{2}$ dentro da folha, e as fendas estomáticas se abrem amplamente, diminuindo a resistência estomática à difusão do $\mathrm{CO}_{2}$ (FLEXAS et al. 2012). Nessas condições, há elevada perda de água por transpiração, porém, uma vez que o suprimento hídrico é abundante, torna-se vantajoso para a planta intercambiar a água por produtos da fotossíntese, resultando em ganho no crescimento (FAN et al. 2015).

\section{Conclusões}

Os biofertilizantes compostos de rizobactérias e composto de Trichoderma asperrellum aceleraram o crescimento e aumentaram a eficiência fotossintética em mudas de açaizeiro.

O biofertilizante a base de Trichoderma asperrellum acelerou o crescimento de em mudas de açaizeiro e trocas gasosas.

A inoculação das rizobactérias (R-46; R-55; R-58; R-61 e R-92) e o Mix de Trichoderma (T06; T09; T12 e T52) pode contribuir para o manejo sustentável da produção de mudas de açaizeiro em viveiros, pois agem como promotores de crescimento e aumenta a eficiência fotossintética em mudas de açaizeiro 


\section{Referências}

ADESEMOYE A O, TORBERT H A \& KLOEPPER J W. Plant growthromoting rhizobacteria allow reduced application rates of chemical fertilizers. Microb. Ecol. 58: 921-929, 2009.

ALEXANDRE, D.; CUNHA, R. L.; HUBINGER2, M. D. Conservação do açaí pela tecnologia de obstáculos. Ciência Tecnologia Alimentos, Campinas, v. 24, n. 1, p. 114-119, 2004.

BAIS HP, WEIR TL, PERRY LG, et al. The Role of Root Exudates in Rhizosphere Interactions With Plants and Other Organisms. Annu Rev Plant Biol 57:233-266. doi: 10.1146/annurev.arplant.57.032905.105159, 2006.

BUENO, A. C. S. O.,; CASTRO, GLEDSON L. S.; REGO, M. C. F.; BATISTA, T. F. V.; FILLIPE, M.C.C.; M. C. C.; SILVA, G. B. Trichoderma reduces scald and protects the photosynthetic apparatus in rice plants. Biocontrol Science and Technology (Print), v. xx, p. $1-12,2017$.

CARVAlHO, D. D. C.; MELlO, S. C. M.; LOBO JUNIOR, M.; GERALDINE, A. M. Biocontrol of seed pathogens and growth promotion of common bean seedlings by Trichoderma harzianum. Pesquisa Agropecuária Brasileira, Brasília-DF, v. 46, n. 8, p. 822828, 2013.

CASTRO, G. L. S. et al. Anthracnose in açaí palm leaves reduces leaf gas exchange and chlorophyll a fluorescence. Tropical Plant Pathology, v. 42, n. 1, p. 13-20, 2017.

CHAUDHARY, S. R.; SINDHU, S. S. Growth stimulation of clusterbean (Cyamopsis tetragonoloba) by coinoculation with rhizosphere bacteria and Rhizobium. Legume Research - An International Journal, v. 39, n. OF, p. 1003-1012, 2016.

COMISSÃO ESTADUAL DE SEMENTES E MUDAS DO PARÁ (Belém, PA). Normas técnicas e padrões para a produção de mudas fiscalizadas no Estado do Pará. Belém, 1997. 40p

DODD IC, ZINOVKINA NY, SAFRONOVA VI, BELIMOV AA (2010) Rhizobacterial mediation of plant hormone status. Ann Appl Biol 157:361-379. doi: $10.1111 / \mathrm{j} .17447348 .2010 .00439$. 
DONI F, ISAHAK A, CHE MOHD ZAIN CR, WAN YUSOFF WM. Physiological and growth response of rice plants (Oryza sativa L.) to Trichoderma spp. inoculants. AMB Express 4:45. doi: 10.1186/s13568-014-0045-8, 2014.

FAN X, HU H, HUANG G, et al. Soil inoculation with Burkholderia sp. LD-11 has positive effect on water-use efficiency in inbred lines of maize. Plant Soil 390:337-551 349. doi: 10.1007/s11104-015-2410-z, 2015.

FILIPPI MCC, DA SILVA GB, SILVA-LOBO VL, et al. Leaf blast (Magnaporthe oryzae) suppression and growth promotion by rhizobacteria on aerobic rice in Brazil. Biol Control 58:160-166. doi: 10.1016/j.biocontrol.2011.04.016, 2011.

FLEXAS J, BARBOUR MM, BRENDEL O, et al. Mesophyll diffusion conductance to CO2: An unappreciated central player in photosynthesis. Plant Sci 193-194:70-84. doi: 10.1016/j.plantsci.2012.05.009, 2012.

GEORGE P, GUPTA A, GOPAL M, et al. Multifarious beneficial traits and plant growth promoting potential of Serratia marcescens KiSII and Enterobacter sp. RNF 267 isolated from the rhizosphere of coconut palms (Cocos nucifera L.). World J Microbiol Biotechnol 29:109-117. doi: 10.1007/s11274-012-1163-6, 2013.

GLICK, B. R. Plant Growth-Promoting Bacteria: Mechanisms and Applications. Scientifica, v. 2012, p. 1-15, 2012.

HALDAR, S.; SENGUPTA, S. Plant-microbe Cross-talk in the Rhizosphere: Insight and Biotechnological Potential. The Open Microbiology Journal, v. 9, n. iii, p. 1-7, 2015.

HOYOS-CARVAJAL, L.; ORDUZ, S. E BISSETT, J. Growth stimulation in bean (Phaseolus vulgaris L.) by Trichoderma. Biological Control, 51: 409-416, 2009.

KADO CI, HESKETT MG. Selective Media for Isolation of Agrobacterium, Corynebacterium, Erwinia, Pseudomonas, and Xanthomonas. Phytopathology 60:969. doi: 10.1094/Phyto-60-969, 1970.

KANG SM, KHAN AL, YOU YH, et al. Gibberellin production by newly isolated strain Leifsonia soli SE134 and Its potential to promote plant growth. J Microbiol Biotechnol 24:106-112. doi: 10.4014/jmb.1304.04015, 2014.

MARTINS-CORDER, M. P.; SALDANHA, C. W. Germinação de sementes e crescimento de plântulas de diferentes progênies de Euterpe edulis Mart. Revista Árvore, v. 30, n. 5, p. $693-$ 699, 2006.

MARTINS, C. C.; NAKAGAWA, J.; BOVI, M. L. Avaliação da qualidade fisiológica de sementes de açaí. Revista Brasileira de Fruticultura, v. 31, n. 1, p. 231-235. 2009.

Ministério da Agricultura, Pecuária e Abastecimento. Delegacia Federal de Agricultura no Pará. Comissão Estadual de Sementes e Mudas do Pará. Normas técnicas e padrões para a produção de mudas fiscalizadas no Estado de Pará. Belém, 1997. 40p. 
MUKHERJEE, M.; MUKHERJEE, M. P.; HORWITZ, B.; ZACHOW, C.; Berg, G.; ZEILINGER, S. Trichoderma-Plant-Pathogen Interactions: Adv. Genet. Biol. Cont. 52:522$529,2012$.

NASCIMENTO, W. Conseqüências fisiológicas da dessecação em sementes de açaí (Euterpe oleracea Mart.). Revista Brasileira de sementes, Brasília, DF, n. 2, p. 38-43, 2007.

NASCENTE AS, DE FILIPPI MCC, LANNA AC, et al. Biomass, gas exchange, and nutrient contents in upland rice plants affected by application forms of microorganism growth promoters. Environ Sci Pollut Res 24:2956-2965. doi: 10.1007/s11356-016-8013-2, 2016.

OLIVEIRA LC, OLIVEIRA MSP, DAVID E LC, TORRES GA. Karyotype and genome size in Euterpe Mart. (Arecaceae) species. Comp Cytogenet 10:17-25, 2016

OLIVEIRA, M do S.P de; CARVALHO, J.E.U.; NASCIMENTO, W.M.O.; MÜLLER, C.H. Cultivo do açaizeiro para produção de frutos. Belém: Embrapa Amazônia Oriental. 17 p. (Embrapa Amazônia Oriental. Circular técnica, 26), 2002.

OLIVEIRA, M. D. S. P.; NETO, J. T. D. F. Cultivar BRS-Pará: Açaizeiro para Produção de Frutos em Terra Firme. Embrapa, Comunicado Técnico, v. 114, n. 1, p. 1-3, 2004.

OM AC, GHAZALI AHA, KENG CL, ISHAK Z. Microbial inoculation improves growth of oil palm plants (Elaeis guineensis Jacq.). Trop Life Sci Res 20:71-77, 2009.

QUEIROZ, J.A.L.; MOCHIUTTI, S. Cultivo de açaizeiros e manejo de açaizais para produção de frutos. Macapá: Embrapa Amapá, 2001. 33 p. (Embrapa Amapá. Documentos, 30)

RAIS A, SHAKEEL M, HAFEEZ FY, HASSAN MN. Plant growth promoting rhizobacteria suppress blast disease caused by Pyricularia oryzae and increase grain yield of rice. Bio Control 61:769-780. doi: 10.1007/s10526-016-9763-Y, 2016.

RIBEIRO, J. C. et al. Evaluation of the genotoxic and antigenotoxic effects after acute and subacute treatments with açai pulp (Euterpe oleracea Mart.) on mice using the erythrocytes micronucleus test and the comet assay. Mutation Research - Genetic Toxicology and Environmental Mutagenesis, v. 695, n. 1-2, p. 22-28, 2010.

\section{ROSTAMIKIA Y, KOUCHAKSARAEI MT, ASGHARZADEH A, RAHMANI A.} Biomass allocation, leaf gas exchange and nutrient uptake of hazelnut seedlings in response to Trichoderma harzianum and Glomus intraradices inoculation. Journal of forest science, 63, 219-226, 2017.

RUFINO, M. DO S. M. et al. Açaí (Euterpe oleraceae) "BRS Pará": A tropical fruit source of antioxidant dietary fiber and high antioxidant capacity oil. Food Research International, v. 44, n. 7, p. 2100-2106, agosto. 2011. 
SHI Y, LOU K, LI C. Growth and photosynthetic efficiency promotion of sugar beet (Beta vulgaris L.) by endophytic bacteria. Photosynth Res 105:5-13. doi: 10.1007/s11120-0109547-7, 2010.

SILVA CRAVO M, VIÉGAS IJM, BRASIL EC (2007) Recomendações de adubação e calagem para o Estado do Pará. EMBRAPA Amazonia Oriental, Bélem, PA (Brasil).

SILVA, J. C.; TORRES, D. B.; LUSTOSA, D. C.; FILIPPI, M. C. C.; SILVA, G. B. Rice sheath blight biocontrol and growth promotion by Trichoderma isolates from the Amazon. Amazonian Journal of Agricultural and Environmental Sciences, Belém-PA, v. 55, n. 4, p. 243-250, 2012.

SILVESTRE WVD, PINHEIRO HA, SOUZA RORDM, PALHETA LF.Morphological and physiological responses of açaí seedlings subjected to different watering regimes. Revista Brasileira de Engenharia Agrícola e Ambiental. 2016, vol. 20, n.4, p.364-371.

VAN LOON LC. Plant responses to plant growth-promoting rhizobacteria. Eur J Plant Pathol 119:243-254. doi: 10.1007/s10658-007-9165-1, 2007.

ZHANG K, LIU Z, SHAN X, et al. Physiological properties and chlorophyll biosynthesis in a Pak-choi (Brassica rapa L. ssp. chinensis) yellow leaf mutant, pylm. Acta Physiol Plant 39:22. doi: 10.1007/s11738-016-2321-5, 2017. 